Nota Bene: Canadian Undergraduate Journal of Musicology

\title{
"Up Close and Intimate": Catharsis, the Dark Side of Sexuality, and The Dresden Dolls
}

Logan Anne Imans

Wilfrid Laurier University

\section{Recommended Citation}

Imans, Logan Anne. "“Up Close and Intimate”: Catharsis, The Dark Side of Sexuality, and The Dresden Dolls." Nota Bene: Canadian Undergraduate Journal of Musicology Vol. 13, no. 1 (2020): 1-24. DOI 10.5206/notabene.v13i1.8559 


\title{
"Up Close and Intimate": Catharsis, the Dark Side of Sexuality, and The Dresden Dolls
}

\begin{abstract}
The Dresden Dolls are a punk-cabaret band that use their music to delve into diverse and taboo subject matter including sexual assault, abortion, and trauma. Despite the morose and grotesque imagery invoked by their lyrics, this paper advocates for the therapeutic effects of catharsis as encouraged by The Dresden Dolls. This essay provides an overview of the applications of catharsis in the arts and psychotherapy, explores how the musical elements and performance contexts of punk-cabaret elicit catharsis, and develops a contemporary theory of catharsis as it pertains to the music of The Dresden Dolls. In considering manifestations of trauma and healing in the songs "Missed Me," "Mandy Goes to Med School," and "Lonesome Organist Rapes Page Turner," this paper illustrates how, despite the potential challenges of confronting trauma through music, the approach of The Dresden Dolls is ultimately effective in cultivating catharsis and encouraging healing for their listeners.
\end{abstract}

\section{Keywords}

Dresden Dolls, punk-cabaret, catharsis, sexuality, trauma, healing 


\title{
"Up Close and Intimate": Catharsis, the Dark Side of Sexuality, and The Dresden Dolls
}

\author{
Logan Anne Imans \\ Year IV - Wilfrid Laurier University
}

"I've been getting up close and intimate" - these lyrics uttered by The Dresden Dolls in their song "Mandy Goes to Med School" would seem to suggest a positive, even desirable, sexual encounter. ${ }^{1}$ So, when the subject turns to back-alley abortion, we are shocked to uncover a darker side of sexuality that is portrayed by the band's grotesque musical aesthetic. Fusing the confrontational style of punk rock with the satirical irony of goth music, the band explores themes of sexual assault and traumatic repression through a unique genre that they describe as "punkcabaret." Their songs explore uncomfortable topics in order to purposely unsettle, relieve, and transform the listener's relationship with strong emotions, particularly in the wake of traumatic experiences. While the music of The Dresden Dolls seems deviant and perverse to some, its effect is undeniably cathartic. In this paper, I argue that the genre of punk-cabaret is a

1 The Dresden Dolls, "Mandy Goes to Med School," track 11 on Yes, Virginia, Roadrunner Records, 2006, compact disc. 
safe and effective platform through which the healing powers of catharsis can be experienced through music. Through an analysis of the lyrical content, musical elements, and performance contexts of The Dresden Dolls' songs "Missed Me," "Mandy Goes to Med School," and "Lonesome Organist Rapes Page Turner," I show that, despite the negative imagery of the songs, the band's "up close and intimate" nature provides a venue for validation and healing for the listener.

The Dresden Dolls, comprised of singer-pianist Amanda Palmer and drummer Brian Viglione, formed in Boston, Massachusetts in 2000. As Palmer explains, they chose the label "punk-cabaret" to capture a kind of "theatrical, intimate, balls-out energy and intensity that sort of destroys all in its path." 2 The band's destructive musical intensity and assertive performance energy is informed by the political and underground capital of the genre of punk rock, while the ambiguous gender presentation and implicit sexual transgressions present in the theatrics of The Dresden Dolls' performances in intimate venues is inspired by the Weimar-era cabaret tradition. Through satirical lyric delivery on grotesque subject matter, punk-cabaret also draws influence from goth subculture, in which a murky sonic ambience and romanticized treatment of death exude the extreme emotionalism that is characteristic of this musical genre. Exploring the dark sides of their lives through their music, The Dresden Dolls create an outlet for expressing overwhelming emotions and unbearable experiences. The environment they create through their live

\footnotetext{
2 "The Rise and Times of The Dresden Dolls EPK (Part 2 of 3)," filmed 2004, posted by "dresdendolls," Youtube video, 4:49, posted January 3, 2007, https://www.youtube.com/watch?v $=$ vpvKuFwaOdk.
} 
shows also extends such emotional release to their audience, fostering a platform for catharsis and healing through their music.

Catharsis has a lengthy history of association with emotional release and with connotations of healing. In ancient Greece, the term "catharsis" was conceived to describe the physical act of purging in medicine and ritual. ${ }^{3}$ Aristotle introduced the word in reference to menstruation, but later applied it to the arousal and purgation of strong feelings, like fear and pity, which occurred through watching Greek tragedy. ${ }^{4}$ Theatrical portrayals of overwhelming feelings precipitate the spectators into similar states as those shown onstage, eliciting crying, shaking, and applauding as emotional discharge. In being affected insofar as they identify with the characters and action presented onstage, audience members can confront and resolve issues that trouble them in their own lives. ${ }^{5}$ The Dresden Dolls take a similar approach to emotional release by exploring common narratives of trauma in their music. This exploration assists the listener in distancing traumatic events, thereby experiencing catharsis as a therapeutic emotional release.

In psychotherapy, it is acknowledged that identification with strong emotions is not enough to resolve trauma - the

\footnotetext{
${ }^{3}$ Merriam-Webster Dictionary Online, s.v. "catharsis," accessed November 13, 2018, https://www.merriam-

webster.com/dictionary/catharsis?utm campaign=sd\&utm medium=serp\&ut $\underline{m}$ source $=$ jsonld.

${ }^{4}$ Velvet Yates, "A Sexual Model of Catharsis," Apeiron 31, no.1 (1998): 36, doi:10.1515/APEIRON.1998.31.1.35.

${ }^{5}$ Stefan Meisiek, "Which Catharsis Do They Mean? Aristotle, Moreno, Boal and Organization Theatre," Organization Studies 25, no.5 (2004): 797, 802. https://doi.org/ 10.1177/0170840604042415.
} 
intention for healing and the construction of narrative must also be present. ${ }^{6}$ Catharsis in psychotherapy was first explored in the early twentieth century by psychoanalysts Joseph Breuer and Sigmund Freud, who sought to relieve female patients from posttraumatic symptoms labelled as "hysteria." Through hypnosis of the patient, repressed memories of trauma were thought to emerge and be exorcised through emotional ventilation. While this method of catharsis was largely discredited due to Breuer's and Freud's lack of success in permanently remedying posttraumatic stress symptoms, they made pivotal discoveries about the importance of creating narrative to heal from trauma. ${ }^{7}$ Paired with emotional release, constructing a narrative about trauma and its effects enables individuals to begin to make sense of their experiences and integrate them into their overall personal narrative. Traumatic narrative connects to Jacques Lacan's belief that people can only survive a catastrophe if they fictionalize it in some way. ${ }^{8}$ Not to be confused with the construction of false memories, the fictionalization of a traumatic event refers to the ability to see trauma as separate from oneself, instead of as an inextricable and irreversible part of one's reality. Thus, fictionalization by way of creating narrative enables the individual to distance themselves from the trauma and see it as a place for growth and healing. ${ }^{9}$ In this way, we can understand that The

${ }^{6}$ Irvin D. Yalom, The Theory and Practice of Group Psychotherapy, 4th edition (New York: Basic Books - Harper Collins, 1995), 80.

${ }^{7}$ Katharina Gerstenberger and Tanja Nusser, eds., Catastrophe and Catharsis: Perspectives on Disaster and Redemption in German Culture and Beyond (New York: Camden House, 2015), 7.

${ }^{8}$ Gerstenberger and Nusser, Catastrophe and Catharsis, 3.

${ }^{9}$ Peter Levine, In an Unspoken Voice: How the Body Releases Trauma and Restores Goodness (Berkeley: North Atlantic Books, 2010), 36. 
Dresden Dolls seek to distance trauma by way of storytelling through theatre, art, and music. This affords the listener the opportunity to experience emotional discharge alongside musical entertainment, and benefit from the therapeutic potential of catharsis and narrative.

In the twentieth century, German playwright and cabaret contributor Bertolt Brecht rejected catharsis as a passive ventilation of "cheap" emotions that prevented audience members from thinking critically about the drama, and instead endorsed an "alienation" technique to discourage emotional involvement. Challenging Aristotle's idea of resolution through identification, Brecht believed that identification with characters onstage led to feelings of complacency instead of responsibility. He argued that only through emotional detachment and recognition of larger social and political issues could the audience feel compelled to make changes in their lives. ${ }^{10}$ Indeed, Brecht's development of the alienation technique sought to discourage what he considered to be "catharsis" in the genre of epic theatre. In deviating from dramatic conventions, Brecht's works incorporated harsh and unnatural stage lighting, the verbalization of stage directions, and explanatory placards dictating audience reactions. He also instructed actors to "break the fourth wall" and address the audience directly as a reminder that what they are seeing onstage is a construction of reality, not reality itself. ${ }^{11}$ However, instead of trying to provide escape or relief from reality, this form of epic theatre sought to afford the audience a deeper understanding of their seemingly mundane life situations

\footnotetext{
${ }^{10}$ Bertolt Brecht, Brecht on Theatre: The Development of an Aesthetic, edited and translated by John Willet (London: Methuen, 1964), 87.

${ }^{11}$ Brecht, 180.
} 
and force them to see the world differently by disorienting their senses and ability for rational thought. Alongside Brecht's contributions to the genre of cabaret, The Dresden Dolls' punkcabaret musical aesthetic is based on a post-modern combination of the alienation technique and catharsis, which views its emotional effects as having positive healing potential.

The Dresden Dolls borrow aspects of alienation from Brecht's work in their musical juxtaposition of styles and their politically-charged performances, often including intentional wrong notes, audience engagement akin to breaking the fourth wall, and overly harsh stage lighting to emphasize their position as a musical spectacle. However, unlike Brecht, their music does not serve primarily as social critique, nor does it seek to discourage identification. Instead, the music of The Dresden Dolls is a vehicle for personal reflection and development, as the band views identification to be an asset to the music's healing potential. ${ }^{12}$ Catharsis achieved through identification with characters and narrative is not simply the release of superficial emotions. Rather, it causes a deeper psychological shift in which the audience can feel a personal responsibility to release and heal trauma, using the music as encouragement and support along the way. As such, the remainder of this paper will be devoted to a consideration of catharsis as a musical phenomenon, including an in-depth discussion of how catharsis manifests in the lyrical content, musical elements, and performance contexts of The Dresden Dolls.

\footnotetext{
12 "The Rise and Times of The Dresden Dolls EPK (Part 3 of 3), filmed 2004, posted by "dresdendolls", Youtube video, 2:40, posted January 3, 2007, https://www.youtube.com/watch?v $=\mathrm{Y} 7 \mathrm{tbX} 4 \mathrm{nt} 8$.
} 
The Dresden Dolls' invention of the genre of punkcabaret uses musical elements to startle, unsettle, and disorient the listener, thus seeking to produce a physiological release through crying, shaking, and yelling. Based on these effects, my discussion of catharsis relies on musical markers including repetitive, aggressive rhythms, a wide range of dynamics with particularly forceful loud sections, and jarring or unexpected sounds; a song's lyrical content, including graphic themes, alternation of narrative voices, and confrontational language; and a song's performance style, including audience participation, dramatization of the song's meaning, and room for improvisation. This is not to say that other musical elements are devoid of cathartic potential, but my criteria for catharsis in this paper is based on these characteristic features of the music of The Dresden Dolls.

While catharsis has been studied in relation to theatre and psychotherapy, its historical presence in music is nebulous. The ancient Greeks wrote about mimesis and catharsis in music, referring to "mimetic" imitation and resemblance of emotional contours in musical gestures in contrast to "cathartic" induction and purification of the soul through music's affect. ${ }^{13}$ Considering the medical nature of the term "catharsis," the inherent "temperament" of the listener was believed to be affected by the depiction of this temperament in music through modes and gestures. Further explored through the Doctrine of Affections in the Renaissance and Baroque era, the physiological effects of music upon the listener were quantified through musical

${ }_{13}$ Patrik N. Juslin and John A. Sloboda, Handbook of Music and Emotion Theory, Research, Applications (Oxford: Oxford University Press, 2010), 47. 
rhetoric. ${ }^{14}$ In the twentieth century, music critic Theodor Adorno distinguished between music that simply expressed pathos in contrast to music that encapsulated catharsis; here, pathos aligns more closely with Brecht's view of catharsis as discharging "superficial" emotions, instead of as having a more substantial impact on the listener. Hailing the music of Schoenberg as the culmination of deeply rooted emotional expression, Adorno considered catharsis to exhibit "genuine emotions of the unconscious - of shock, of trauma - [which] are registered without disguise through the medium of music." 15 Adorno admits that music, as self-expression and identification, can serve a healing function for the listener by arousing emotions and experiences that are deeply stored in the body, aligning with recent scholarly findings on trauma and the impact of shock on one's physiology. ${ }^{16}$

Based on the visceral impact of catharsis on the mind and body, and the healing potential of intentional release, I understand that a cathartic response to music is as dependent on context as it is on characteristics. While music with elements that disturb, disorient, and dysregulate the listener are inherently cathartic in their physical effects on the listener, a personal connection to a song's narrative content, both on the part of the listener and the performer, ensures a deeper cathartic response with a therapeutic impact. If the artist uses the creation of music

\footnotetext{
${ }^{14}$ Dietrich Bartel, Musica Poetica: Musical-Rhetorical Figures in German Baroque Music (Lincoln: University of Nebraska Press, 1997), 29. ${ }^{15}$ Juslin and Sloboda, Handbook of Music and Emotion, 50. ${ }^{16}$ See works including Bessel van der Kolk, The Body Keeps the Score (New York: Viking, 2014); and, Peter Levine In an Unspoken Voice: How the Body Releases Trauma and Restores Goodness (Berkeley: North Atlantic Books, 2010).
} 
as an act of healing for themselves, the music is also undoubtedly cathartic in its effect. In this way, the music becomes an outlet for emotions and healing because of the intention behind its creation. The context of a musical listening experience also impacts a cathartic response. While catharsis is possible in isolated listening to recordings, extreme emotional responses are generated most effectively in group environments; thus, concerts serve as a unique setting to experience events of musical healing through catharsis. Because psychotherapists find that healing through catharsis is most effective as an interpersonal process, music becomes most impactful when experienced with others. ${ }^{17}$

Emphasizing the importance of a supportive group setting in cathartic experiences, Palmer spends as much time connecting with fans after concerts as she does onstage, seeking to transform individual instances of pain into group experiences of collective sharing and healing. ${ }^{18}$ Although listening to The Dresden Dolls in isolation does allow adequate privacy to face memories and feelings that may be associated with shame, guilt, and grief, it is the collective therapeutic experience provided by live shows that attracts many listeners. Being supported by a community of fans provides an understanding of shared human experiences, whether or not personal traumas are directly articulated. This "up close and intimate" nature of the band's interactions with their fanbase is an integral part of the healing potential of catharsis.

${ }^{17}$ Yalom, Group Psychotherapy, 81.

${ }^{18}$ Emma Cosselett, "Music without a Genre: Amanda Palmer and the Secret World of Dark Cabaret. An Ethnographic Study," Popscript Volume II (2015): 69. 
Audience responses to The Dresden Dolls' concerts confirm that emotional release and healing is experienced. The Dresden Dolls fan Loryn Heffner reviewed one of the band's concerts in 2008 and reported that her emotional experience was paramount in her experience of the music, providing her with an emotional outlet that she did not have access to in other areas of her life:

Last night when they performed "Missed Me," my reaction can only be described as cathartic, but in a good way. I have always loved that song because how true it was to me, and to see it performed live, was just so incredibly overwhelming that I could not help but cry...I left the theater feeling numb in a healthy afterglow kind of way. ${ }^{19}$

Heffner's experience is direct evidence for the healing potential of catharsis from The Dresden Dolls' music. Her review illustrates that even though the recorded version of "Missed Me" was powerful, it was the live experience of the song in a group setting that allowed Heffner to experience crying as a healing cathartic release. The group setting of a concert can intensify the meaning of the music and the catharsis that is triggered, as trauma can be recognized as a universal experience instead of as an individual or isolating event. The catharsis enabled by the music of The Dresden Dolls is also affirmed in a 2017 concert review, in which the reporter commended the band for "creating

${ }^{19}$ Wade Tartangelo, "A fan's review of the Dresden Dolls show," Creative Loafing Tampa Bay, posted January 12, 2008, accessed November 21, 2018, https://www.cltampa.com/news-views/article/20736713/a-fans-review-ofthe-dresden-dolls-show. 
a uniquely cathartic, often confrontational sound and vision all their own." 20 The unique and confrontational aesthetic of punkcabaret is what enables The Dresden Dolls to facilitate catharsis and have a positive impact on the emotional healing of their fanbase. To explore the interactions between subject matter, musical setting, and the range of emotions that arise in the music of The Dresden Dolls, I turn now to a discussion of three songs that exemplify the cathartic potential of punk-cabaret.

"Missed Me" is a dramatic and versatile song from The Dresden Dolls' eponymous album released in 2004. The lyrics "missed me, missed me, now you've got to kiss me" conjure up associations with a child's playground taunt, as the song explores an interaction between a morally-questionable man and a precociously derisive young girl. ${ }^{21}$ The repetition of the taunt "missed me" reinforces the young girl's innocence while the repetition of "mister" repositions her awareness of the power imbalance at play. The young girl warns that she will tell her sister, who will tell her mother, who will tell her father who "won't be too happy" and will have the man arrested. While the lyrics have a sensationalist and voyeuristic flavor reminiscent of the Weimar-era cabaret tradition, the sexual endeavor is not explicitly explored in performance and is instead insinuated by the music itself. ${ }^{22}$

${ }^{20}$ Glide Magazine, “The Dresden Dolls Return for Four Shows," posted August 16, 2017, accessed November 21, 2018, https://glidemagazine.com/191377/dresden-dolls-return-four-shows/. ${ }^{21}$ The Dresden Dolls, "Missed Me," track 3 on The Dresden Dolls, Roadrunner Records, 2004, compact disc. ${ }^{22}$ Alan Lareau, "Lavender Songs: Undermining Gender in Weimar Cabaret and Beyond," Popular Music and Society 28, no.1 (2005): 20. 
Vocally, the hushed seductive quality of the first few verses plays up the demure child-like character, while Palmer's dynamic attacks on lyrics like "If you trick me, mister, I will make you suffer," highlight the character's recognition of malintent. This shift in vocal quality adds complexity to the song's lyrics, which leads the listener to question who really is at fault for these inappropriate encounters. Even despite the warning: "I wouldn't miss me, if you get me, mister, see?", the encounter escalates:

Missed me, missed me, now you've gone and done it

Hope you're happy in the county penitentiary

It serves you right for kissing little girls

But I'll visit, if you miss me.

Say you miss me. ${ }^{23}$

The young girl's pernicious words reveal the complications of this scenario of seduction. The naïve alternation of the young girl's warnings and her warped dependence on inappropriate attention lends itself to a reading in which survival mechanisms perpetuated from repeated abuse shape her morally ambiguous actions. The victim's positive attachments to the abuser, or her ability to "play along" with his demands, serve as an attempt to protect her physical wellbeing, while also greatly blurring the victim's internal perceptions of right and wrong. The allure of the young girl in this case of underage seduction clearly contributes to the man's inability to accept responsibility for his actions - a

${ }^{23}$ The Dresden Dolls, "Missed Me." 
common theme in narratives of abuse. The Dresden Dolls take advantage of this identifiable narrative and sonically convey its perversion in their veiled musical treatment of "Missed Me."

"Missed Me" begins with a dark-tango piano accompaniment, over which sounds resembling exhalations and grunts, chaotic tumblings of metal objects, and crinkling paper materials are indistinguishable to the ear and unsettle the listener from the outset. A leap of a major seventh concludes the first iteration of the accompaniment pattern and, unable to provide the moral assurance of an octave, signals to the listener that this song is not to be trusted. When Palmer begins to sing, she opens at a hushed dynamic with shocking interjections of forceful attacks on piano and percussion, contributing to an overall feeling of sneering confrontation. The volume of the extramusical interjections and musical interludes assaults the ear of the listener who has previously leaned in to discern the breathy lyrics. Thus, dynamic unpredictability creates an overall effect of haphazardness and intentional harm, contributing to the cathartic impact of the musical depiction of this common traumatic narrative.

Catharsis can be achieved through identification with the confrontational voice of the young girl in "Missed Me" and is enhanced by the versatility of live shows. The socially relevant aspirations of the punk-cabaret genre allow The Dresden Dolls to change the lyrics of their songs during performances and use audience participation to appeal to the varying experiences of their listeners. In a solo performance of "Missed Me," Palmer called four female audience members to the stage to assist her. She instructed the women to look "angry at a man" and gave them a squeaking pig toy to strangle at obvious points in the 
song, insinuating the revolting nature of sexual predators. ${ }^{24}$ In 2018, during the trial of Harvey Weinstein, Palmer also changed the lyric from "you must want to f*** me" to "you must want to cast me," to draw attention to directors who use their power to manipulate women into sexual encounters at the threatened expense of their careers. ${ }^{25}$ This reference adds further complexity to the song, as the narrator becomes the victim, trapped by a man who knowingly uses coercion to his advantage. By adopting the dialogue as one's own, the listener may be able to project their feelings and experiences onto the song's narrative and thus feel a sense of emotional release and resolution that may not be realistic in their lived situations. Regardless of age, the "young girl" takes on the voice of all women who find themselves in inappropriate encounters where they are made to feel both powerless and guilty for events beyond their control. Through adapting lyrics and involving the audience, The Dresden Dolls encourage recognition of the commonality of traumatic narratives and add a layer of political commentary to the catharsis the songs afford.

In "Mandy Goes to Med School" from The Dresden Dolls' 2006 album "Yes, Virginia," the contentious issue of reproductive rights is explored through a scenario of back-alley abortion. The lyrics are graphic from the first verse - "I've been feeling dull as a coat hanger," and "giddy as a gangbanger" -

24 "Amanda Palmer with Jherek Bischoff - Missed Me - Live at Union Chapel," filmed November 16, 2017, posted by "Amanda Palmer," Youtube video, 7:28, posted November 23, 2017,

https://www.youtube.com/watch?v $=g P T U F T 7 f 7 p Q \& l i s t=P L d C j n 28 n 1$ Ao9Z FGniiI4VT9IgVunnwlJY\&index $=5$.

${ }^{25}$ In October 2018, the music video was released for the song "Mr. Weinstein Will See You Now," written and performed by Amanda Palmer and Jasmine Power available at https://www.youtube.com/watch?v=juubxnkgnS8. 
through to "How about a nine-month long vacation and a twofoot coffin?" 26 The narrative voice switches between different sides of Mandy's personality, beginning with an almost-whispered secretive opening before shifting to a more commanding, assured, and overtly illegal persona with lines like "I've been taking friends to the alleyway" and "I've been getting damn good at hiding it." This satirical exploration of abortion politics relies on grotesque and morose underpinnings. ${ }^{27}$ It involves a flirtation with death and illegal activity which manifests as an absurd and sardonic perception of the threat of returning to unsafe practices of abortion. The line "it's not a bad thing to get professional" reveals that Mandy is on her way to becoming qualified to perform safe, legal abortions but, due to the restrictions of the American healthcare system, ("in some states they say you can burn for it/ but I'll burn that bridge when I get to it'), she must take her chances at delivering abortions to those in need, even if it puts her patients, and her career, at risk.

The song opens with Palmer's hushed vocals over a walking bass line, seducing the listener with a smooth tone and narrow vibrato reminiscent of the Weimar-era cabaret tradition while descending into the ambivalence of the subject matter. Violent interjections of guitar and piano chords on each downbeat emphasize words like "dull" and "giddy," adding tension to the otherwise innocent piano-bar feel. This sinister undertone unsettles the listener and prevents the formation of a clear moral attitude as Mandy never outright admits to the work

\footnotetext{
26 The Dresden Dolls, "Mandy Goes to Med School."

${ }^{27}$ Braun, Edward, "Doctor Dapertutto (1908-1917): The Fairground Booth," in Meyerhold on Theatre (London: Methuen \& Co. Ltd, 1969), 139.
} 
she is doing "out of [her] new SUV." 28 The healing potential of this song lies in its satirical tackling of political issues, with grotesque elements blurring the moral lines associated with abortion in a way that shamelessly liberates the complex experiences of the listener.

A similar satirical approach is taken in the song "Lonesome Organist Rapes Page Turner" from The Dresden Dolls' 2008 album "No, Virginia," which addresses the tension between the repression of traumatic memories, the prevalence of unreported assault, and the culture of victim-blaming. Dripping with ironic insinuation, the lyrics provide a matter-of-fact, almost-sarcastic, narration of an old organ player assaulting his young page turner, with Palmer assuming the voice of both characters. The distressed voice of the page turner, "he jabbed a needle in my neck," alternates with the nasal, malicious voice of the organist, "you can hack my wrists off with your choice of object." ${ }^{29}$ Clear vocal markers contribute to the sonically disorienting feeling of blurred experiences, where the page turner's past and present recollections are triggered by the voice of the organist, although memories are fragmented.

While the page turner is physically and emotionally aware of the assault, many lyrics exhibit mental repression of the traumatic events. For example, the line "If a rock should hit my head/ and I remember what he [the organist] did/ you'll be the very first to know," reveals that the event is simultaneously at the forefront of the page turner's mind in its effects, yet constantly

28 The Dresden Dolls, "Mandy Goes to Med School."

${ }^{29}$ The Dresden Dolls, "Lonesome Organist Rapes Page Turner," track 6 on No, Virginia, Roadrunner Records, 2008, compact disc. 
being denied in its occurrence. ${ }^{30}$ The emphasis on physical details of remembered sensations instead of sequential details of the event aligns with characteristics of traumatic memory and contributes to the page turner's own distrust of their experiences.

Because traumatic memory is fragmented and sensory, thus interpreted as less trustworthy than narrative memory, there is a general lack of disclosure of sexual assault and a prevalence of victim-blaming when assault is addressed. It is the uncertainty arising from a lack of tangible details that prevents the page turner from coming forward about the assault, not a personal disbelief of its occurrence. The final verse of the song encapsulates the situation's ambivalent outcome:

So, several decades have gone by

I am still sitting by his side

I turn the pages faithfully

He turns his head and smiles at me

And with a wink he says, "I doubt

"we would be anywhere without

your gift for keeping truth and consequence from meeting." 31

These lyrics speak to the social culture of victim-blaming; the page turner keeps the assault a secret, afraid of taking the blame

${ }^{30}$ Jenny Olivia Johnson, "The Sounds That Know: Synaesthesia, Sexual Trauma, and a Musicological Confession," Women and Music: A Journal of Gender and Culture, Vol.19 (2015): 134.

31 The Dresden Dolls, "Lonesome Organist Rapes Page Turner." 
or not being believed because of the lack of tangible evidence. Like the page turner, many survivors of assault do not come forward with their story and thus carry with them a sense of guilt and shame for events beyond their control. While there is no obvious emotional resolution in the song, the listener can begin to find support and healing from identifying with the plight of the page turner and releasing their pent-up emotions, instigated by the pounding, unrelenting sound of the punk-driven music.

Catharsis may be triggered in "Lonesome Organist Rapes Page Turner" through the jarring and unexpected sounds of sharp, surprised screams, which usually follow more intense lyric content such as "maybe I'll find out why this damn thing won't stop bleeding." ${ }^{\prime 2}$ The potency of these lyrics is underlined by elements of punk rock, featuring aggressive percussion, a pointed and repetitive chord sequence on piano, piercing vocals featuring audible, ragged breathing, and an overall sense of chaotic energy which matches the dysregulated mental and emotional state of the page turner. Although performances of this song do not showcase much improvisation or audience involvement, "Lonesome Organist Rapes Page Turner" is undeniably cathartic in its upfront exploration of traumatic subject matter and aggressive, though ironic, musical approach.

Because of diverse emotional needs and audience responses, critics may disagree with the claim that the catharsis induced by The Dresden Dolls can provide a positive healing experience. Critics may wonder how songs with disturbing themes can be therapeutic, whether the audience can channel intense emotions triggered at the concert in non-destructive

32 The Dresden Dolls, "Lonesome Organist Rapes Page Turner." 
manners, and whether catharsis can really provide healing. It is important to mention that catharsis does not always serve a healing function; sometimes it is just an emotional release. People generally use the word "catharsis" when referring to emotional outlets in their lives, such as having a good cry or deleting messages from their ex-partner, and there is nothing inherently harmful or destructive about these experiences. However, catharsis could be harmful to people who have experienced trauma if it forces them to examine their past traumatic experiences too directly.

Trauma therapist Peter Levine discourages catharsis among traumatized persons because the intensity of emotional flooding could be re-traumatizing; however, The Dresden Dolls' sensationalist and satirical approach to their music helps to minimize this threat. ${ }^{33}$ Levine's discussion of catharsis pertains primarily to the therapeutic techniques of Freud, whose patients experienced hypnosis accompanied by detailed retellings of their traumatic events. This treatment provoked extreme emotional responses without actually resolving the pervasive post-traumatic symptoms. Contrary to this, however, The Dresden Dolls' music about trauma is distanced enough from an individual's direct traumatic experience that a listener may be able to release pent-up feelings associated with post-traumatic stress, without the risk of re-traumatization. The band's overtly sensationalist treatment of subject matter like abortion and sexual assault is a protective measure that enables the themes of trauma to be musically and theatrically explored without being realistically depicted or posing a threat to individuals still suffering from trauma's impact. The

${ }^{33}$ Levine, In an Unspoken Voice, 312. 
intensity of subject matter in the music of The Dresden Dolls paired with the band's satirical approach provides all listeners, regardless of trauma, the potential for emotional release through laughter or tears. Palmer speaks openly about the role of artists to "make light" in dark times which proves that, instead of being disrespectful or diminishing considerations of trauma's impact, the sensationalist and satirical approach of The Dresden Dolls seeks to transform life-shattering experiences into opportunities for reflection, connection, and release. ${ }^{34}$

With the aid of catharsis and the band's own supportive recognition, a fan at The Dresden Dolls concert who is overwhelmed by their emotions and becomes distressed by the intensity of the music can be assured it is only temporary. The 3minute song will soon be over; the concert will end; their emotions will plateau. Considering that the main criticism of catharsis in psychotherapy is that it does not have permanent effects, catharsis in music seems valuable for its impermanence and repeatability. Seldom does one listen to a song only once, unless it is not found appealing. In this way, those in attendance at a Dresden Dolls concert are usually those who have listened repeatedly to their albums for the temporary therapeutic effects they afford. Listeners at a concert may have a desire for a more community-based cathartic experience which can cause a greater shift in their emotional life and lead them closer to the healing they seek.

34 This was expressly conveyed by Amanda Palmer in her recent live show: There Will Be No Intermission, Queen Elizabeth Theatre, Toronto, Canada, March 23, 2019. 
Drawing from the subcultures of punk rock, goth, and cabaret, The Dresden Dolls use satire to theatrically explore taboo subjects, examine political issues, and intentionally instigate catharsis through music. Illustrated by the aggressive, unexpected, and confrontational elements present in the lyrics, music, and performances of the songs "Missed Me," "Mandy Goes to Med School," and "Lonesome Organist Rapes Page Turner," The Dresden Dolls use the genre of punk-cabaret to effectively explore the dark side of sexuality in a way that is conducive to healing. Through the band's irony and emotional integrity, songs about sexual assault, back-alley abortion, and traumatic repression can become healing experiences for the audience. Catharsis affords the listener an opportunity for emotional release through crying, yelling, laughing, or sharing their story. In connecting to the music, to other members of the audience and fanbase, and to themselves, listeners can begin to acknowledge and release trauma held in the body. While The Dresden Dolls sing that "Life is no cabaret," it cannot be denied that the stage of punk-cabaret is a safe platform to experience catharsis and healing through music. $^{35}$

35 The Dresden Dolls, "Sing," track 13 on Yes, Virginia, Roadrunner Records, 2006, compact disc. 


\section{Bibliography}

Bartel, Dietrich. Musica Poetica: Musical-Rhetorical Figures in German Baroque Music. Lincoln: University of Nebraska Press, 1997.

Braun, Edward. "Doctor Dapertutto (1908-1917): The Fairground Booth.” In Meyerhold on Theatre. London: Methuen \& Co. Ltd, 1969.

Brecht, Bertolt. Brecht on Theatre: The Development of an Aesthetic. Edited and translated by John Willet. London: Methuen, 1964. Twelfth printing 1976.

Brill, Dunja. Goth Culture: Gender, Sexuality and Style. New York: Berg, 2008.

Brown, Jayna, Patrick Deer, and Tavia Nyong'o. "Punk and Its Afterlives." Social Text 116 31, no. 3 (Fall 2013): 1-11.

Cosslett, Emma. "Music without a Genre: Amanda Palmer and the Secret World of Dark Cabaret. An Ethnographic Study." Popscript Volume II (2015): 57-74. https://www.academia.edu/12587208/Popscript Volume II Grad uate Research in Popular Music Studies.

The Dresden Dolls, "Lonesome Organist Rapes Page Turner.” Recorded 2003 - January 2008. Track 6 on No, Virginia. Roadrunner Records, 2008, compact disc.

The Dresden Dolls, "Mandy Goes to Med School." Recorded September 10 20, 2005. Track 11 on Yes, Virginia. Roadrunner Records, 2006, compact disc.

The Dresden Dolls, “Missed Me.” Recorded Summer - Fall 2002. Track 3 on The Dresden Dolls. Roadrunner Records, 2004, compact disc.

The Dresden Dolls, “Sing.” Recorded September 10 - 20, 2006. Track 13 on Yes, Virginia. Roadrunner Records, 2006, compact disc.

dresdendolls. "The Rise and Times of The Dresden Dolls EPK (Part 2 of 3)." Filmed 2004. Youtube video, 4:49. Posted January 3, 2007. https://www.youtube.com/watch?v $=$ vpvKuFwaOdk. 
Up Close and Intimate

dresdendolls. "The Rise and Times of The Dresden Dolls EPK (Part 3 of 3)." Filmed 2004. Youtube video, 2:40. Posted January 3, 2007, https://www.youtube.com/watch?v= Y7 tbX4nt8.

Gerstenberger, Katharina, and Tanja Nusser, eds. Catastrophe and Catharsis: Perspectives on Disaster and Redemption in German Culture and Beyond. New York: Camden House, 2015.

Glide Magazine. "The Dresden Dolls Return for Four Shows." Glide Magazine. Posted August 16, 2017. Accessed November 21, 2018. https://glidemagazine.com/191377/dresden-dolls-return-fourshows/.

Haenfler, Ross. Goths, Gamers, Grrrls: Deviance and Youth Subcultures, 2 nd edition. New York: Oxford University Press, 2013, 2010.

Johnson, Jenny Olivia. "The Sounds That Know: Synaesthesia, Sexual Trauma, and a Musical Confession." Women and Music: A Journal of Gender and Culture 19 (2015): 133-141.

Juslin, Patrik N. and John A. Sloboda. Handbook of Music and Emotion Theory, Research, Applications. Oxford: Oxford University Press, 2010.

Lareau, Alan. "Lavender Songs: Undermining Gender in Weimar Cabaret and Beyond." Popular Music and Society 28, no. 1 (2005): 15-33.

Levine, Peter. In an Unspoken Voice: How the Body Releases Trauma and Restores Goodness. Berkeley: North Atlantic Books, 2010.

Meisiek, Stefan. "Which Catharsis Do They Mean? Aristotle, Moreno, Boal and Organization Theatre." Organization Studies 25, no.5 (2004): 797816, https:// doi.org/ 10.1177/0170840604042415.

Merriam-Webster Dictionary Online, s.v. "catharsis". Accessed November 13, 2018. https://www.merriamwebster.com/dictionary/catharsis?utm campaign $=$ sd\&utm mediu $\underline{m}=$ serp\&utm source $=$ jsonld.

Palmer, Amanda. ““'Amanda In The Kitchen” - An Impromptu Interview by Wojtek Gwiazda.” Interview by Wojtek Gwiazda, 8ft records, July 
30th, 2003. Boston. Youtube video, 21:57. Posted August 4, 2015. https://www.youtube.com/watch?v=nkyoQRSlg3I.

Palmer, Amanda. "Amanda Palmer with Jherek Bischoff - Missed Me - Live at Union Chapel." Filmed November 16, 2017. London. Youtube video, 7:28. Posted November 23, 2017. https://www.youtube.com/watch? $\mathrm{v}=\mathrm{gPTUFT} 7 \mathrm{f} 7 \mathrm{pQ} \&$ list $=\mathrm{PLdCjn}$ 28n1Ao9ZFGniiI4VT9IgVunnwlJY\&index $=5$.

Palmer, Amanda and Brian Viglione. "The Dresden Dolls talk w Erik Blair in Bed 2004." Interview by Erik Blair. Blairing Out Show, 2014. Youtube video, 24:11. Posted May 26, 2017. https://www.youtube.com/watch? $v=\mathrm{mAaSwhHDjPE}$.

Tatangelo, Wade. "A fan's review of the Dresden Dolls show." Creative Loafing Tampa Bay. Posted January 12, 2008. Accessed November 21, 2018. https://www.cltampa.com/newsviews/article/20736713/a-fans-review-of-the-dresden-dolls-show.

Yalom, Irvin D. The Theory and Practice of Group Psychotherapy, 4th edition. New York: Basic Books - Harper Collins, 1995.

Yates, Velvet. “A Sexual Model of Catharsis." Apeiron 31, no.1 (1998): 35-58. doi:10.1515/APEIRON.1998.31.1.35. 